\title{
Gas Permeability of Hyperthin Polyelectrolyte Multilayers Having Matched and Mismatched Repeat Units
}

\author{
Song Yi, Cen Lin, William Leon, Dmitri Vezenov and Steven L. Regen \\ $\dagger$ Department of Chemistry, Lehigh University, Bethlehem, Pennsylvania 18015 \\ * email: slr0@lehigh.edu
}

\section{Supporting Information}

Table of Contents

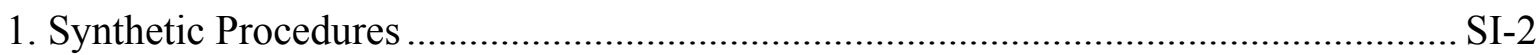

2. Growth Profiles of PEMs …….............................................................................. SI-6

3. Advancing Contact Angles of PEMs ............................................................................... SI-6

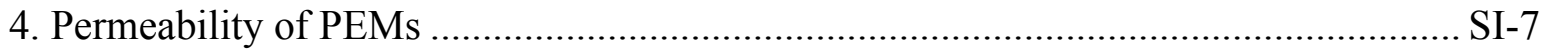

5. Effective Young's Modulus from Nanoindentation Measurements ............................... SI-8

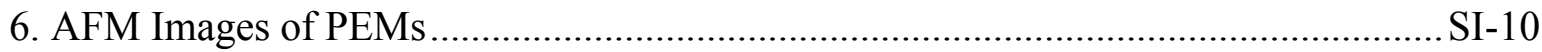

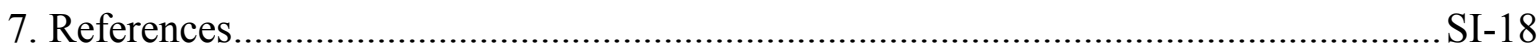




\section{Synthetic Procedures}

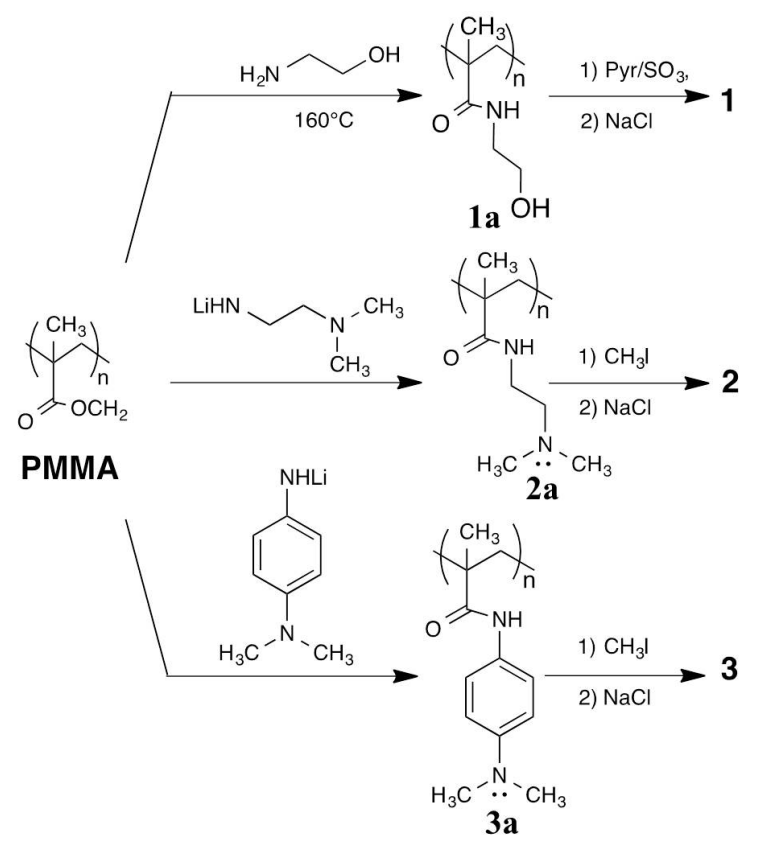

\section{Scheme SI-1}

Synthesis of 1a: Poly(methyl methacrylate) $\left(\mathrm{M}_{\mathrm{w}}: 100 \mathrm{~K}, 0.4 \mathrm{~g}, 4.00 \mathrm{mmol}\right)$ and ethanolamine $(10 \mathrm{~mL}, 165.7 \mathrm{mmol})$ were added in a $50 \mathrm{~mL}$ round-bottomed flask, and the reaction mixture heated at $160{ }^{\circ} \mathrm{C}$ for $48 \mathrm{~h}$. The product mixture was then poured into $200 \mathrm{~mL}$ of acetone to precipitate the polymer. Subsequent washing of the polymer (two times) with $30 \mathrm{~mL}$ of acetone, drying under reduced pressure afforded 1a as a colorless solid (420 mg, yield: 81.4\%) having ${ }^{1} \mathrm{H}$ NMR (500 MHz, $\mathrm{D}_{2} \mathrm{O}$ ): $\delta 3.68$ (brs, 2H), 3.28 (brs, 2H), 2.2-1.5 (brm, 2H), $1.5-0.8$ (brm, 3H).

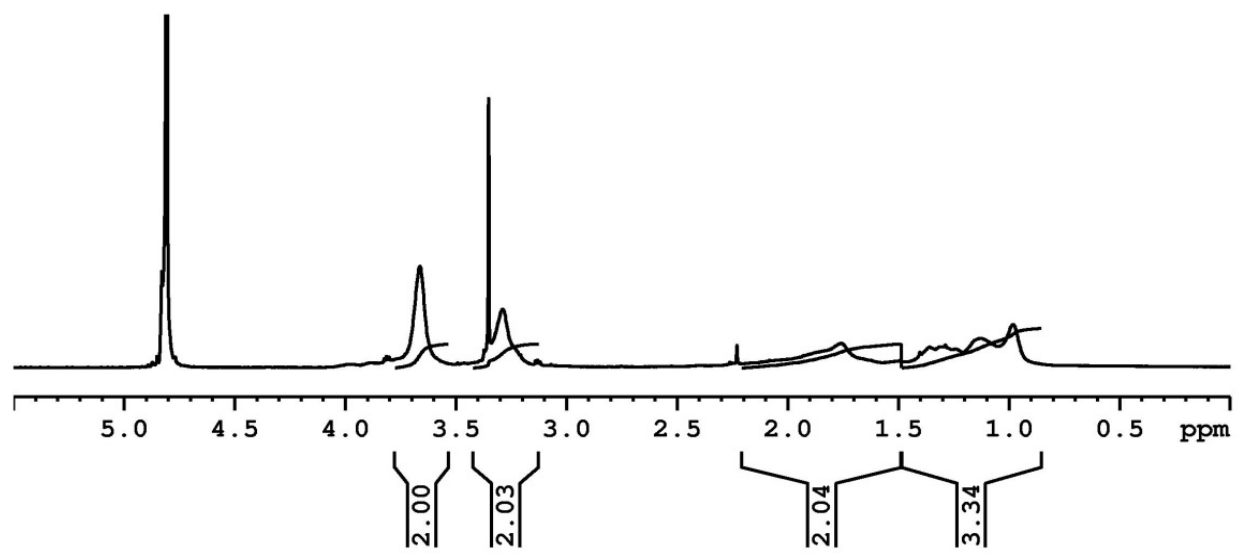

Figure SI-1: ${ }^{1} \mathrm{H}$ NMR spectrum of $\mathbf{1 a}$ 
Synthesis of 1: To a solution that was made by dissolving polymer 1a (400 mg, $3.10 \mathrm{mmol})$ in $10 \mathrm{~mL}$ anhydrous DMF was added sulfur trioxide/pyridine complex (1.48 g, $7.82 \mathrm{mmol})$. The resulting solution was stirred at room temperature for $12 \mathrm{~h}$, and then added, dropwise, to $20.7 \mathrm{~mL}$ of a $1 \mathrm{M}$ aqueous solution of $\mathrm{NaHCO}_{3}$. The resulting solution was then poured into $300 \mathrm{~mL}$ of acetone to precipitate the polymer. Recovery of the polymer by centrifugation, followed by washing (two times) with $30 \mathrm{~mL}$ of acetone, afforded a crude product that was then dissolved in $10 \mathrm{~mL}$ of water. This aqueous solution was then dialyzed against $2 \mathrm{~L}$ of 0.1 $\mathrm{M} \mathrm{NaCl}$ solution for $24 \mathrm{~h}$, followed by additional dialysis against deionized water for $48 \mathrm{~h}$ using a Float-A-Lyzer (Spectra/Por), equipped with a Biotech cellulose ester membrane (MWCO: 3.5 - $5 \mathrm{KD}$ ). Subsequent lyophilization afforded $450 \mathrm{mg}$ (62.8\%) of 1 as a colorless solid having ${ }^{1} \mathrm{H}$ NMR (500 MHz, $\mathrm{D}_{2} \mathrm{O}$ ): $\delta 4.16$ (brs, 2H), 3.52 (brs, 2H), 2.5-1.5 (brm, 2H), 1.5-0.8 (brm, 3H). Anal. Calcd for $\mathrm{C}_{6} \mathrm{H}_{10} \mathrm{NSO}_{5} \mathrm{Na} \cdot 0.75 \mathrm{H}_{2} \mathrm{O}$ (repeat unit): C, 29.45; H, 4.74; N, 5.72. Found: C, 29.49; H, 4.98; N, 5.31.

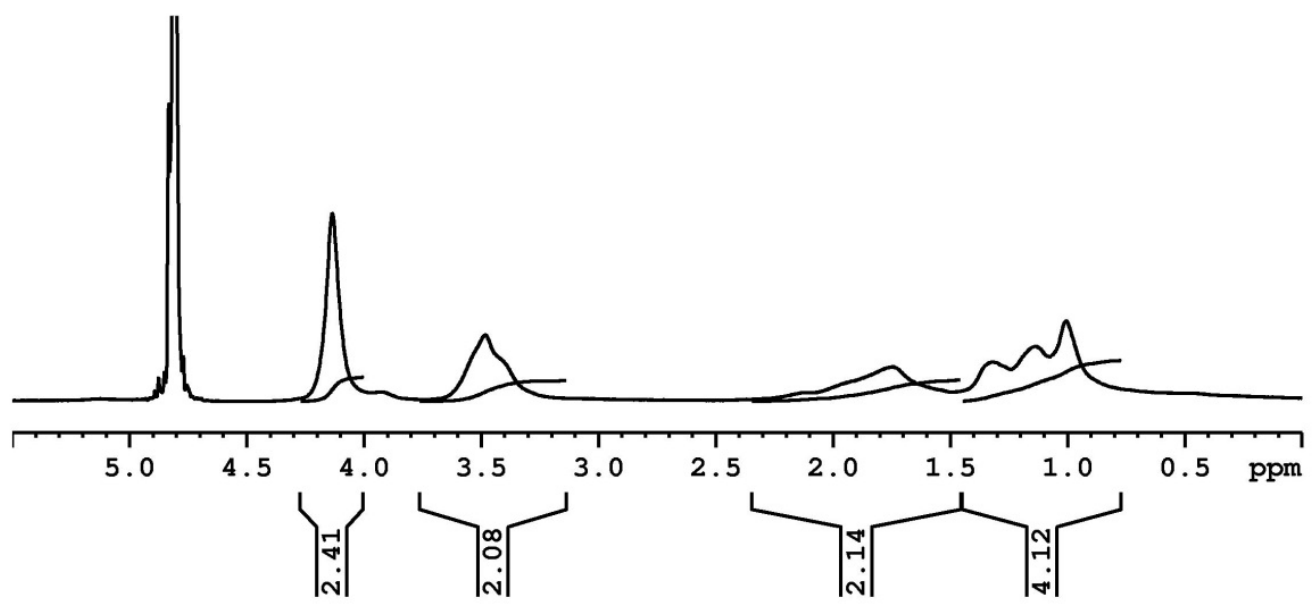

Figure SI-2: ${ }^{1} \mathrm{H}$ NMR spectrum of 1

Synthesis of 2a: To a solution of N,N-dimethylethylenediamine (1.76 g, $20.0 \mathrm{mmol})$ in 20 $\mathrm{mL}$ of anhydrous THF was added $8.0 \mathrm{~mL}$ of a $2.5 \mathrm{M}$ solution of $n$-butyl lithium solution in hexane ( 1 equiv) under $\mathrm{N}_{2}$ atmosphere at $0{ }^{\circ} \mathrm{C}$. To this mixture was then added a solution of PMMA ( $\left.\mathrm{M}_{\mathrm{w}}: 100 \mathrm{~K}, 0.4 \mathrm{~g}, 4.00 \mathrm{mmol}\right)$ in $40 \mathrm{~mL}$ of THF. The reaction mixture was stirred at room temperature for $24 \mathrm{~h}$, and then poured into $200 \mathrm{~mL}$ of diethyl ether to precipitate the polymer. Purification was carried out by dissolution and precipitation (two times) using $5 \mathrm{~mL}$ of methanol and $40 \mathrm{~mL}$ of ether, respectively. The resulting polymer $\mathbf{2 a}$ was obtained as a 
yellow solid (600 mg, yield: 96.8\%) having ${ }^{1} \mathrm{H}$ NMR (500 MHz, $\mathrm{D}_{2} \mathrm{O}$ ): $\delta 3.18$ (brs, 2H), 3.28 (brs, 2H), 2.2-1.5 (brm, 2H), 1.5-0.8 (brm, 3H).

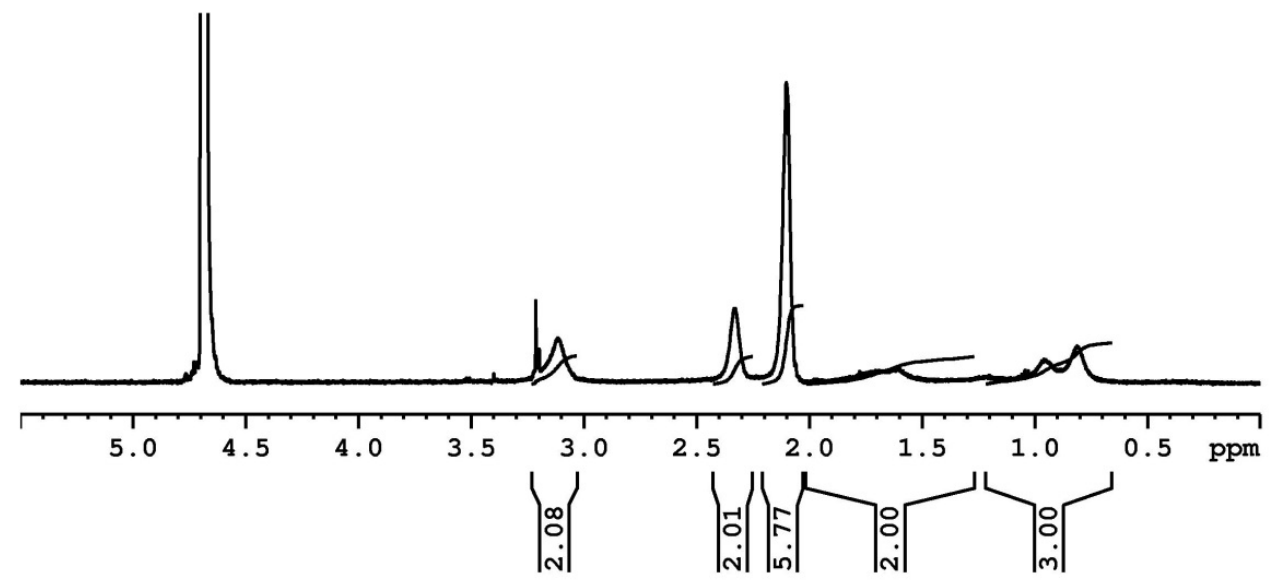

Figure SI-3: ${ }^{1} \mathrm{H}$ NMR spectrum of $\mathbf{2 a}$

Synthesis of 2: Polymer 2a (600 mg, $3.50 \mathrm{mmol})$ and iodomethane $(11.8 \mathrm{~g}, 83.1 \mathrm{mmol})$ were dissolved in $30 \mathrm{~mL}$ of methanol/water $(2 / 1 \mathrm{v} / \mathrm{v})$ and stirred at room temperature for $24 \mathrm{~h}$. The solvent was then removed under reduced pressure, and the residue dissolved in $20 \mathrm{~mL}$ of deionized water and dialyzed, sequentially, against $2 \mathrm{~L}$ of a $0.1 \mathrm{M} \mathrm{NaCl}$ solution for $24 \mathrm{~h}$ and deionized water for $48 \mathrm{~h}$. Subsequent lyophilization afforded $580 \mathrm{mg}(80 \%)$ of 2 as a yellow solid having ${ }^{1} \mathrm{H}$ NMR (500 MHz, $\mathrm{D}_{2} \mathrm{O}$ ): $\delta 3.68$ (brs, 2H), 3.52 (brs, 2H), 3.26 (s, 9H), 2.2-1.5 (brm, 2H), 1.5-0.7 (brm, 3H). Anal. Calcd for $\mathrm{C}_{6} \mathrm{H}_{11} \mathrm{NO}_{2} \cdot 2 \mathrm{H}_{2} \mathrm{O}$ (repeat unit): C, 44.53; $\mathrm{H}$, 9.55; N, 11.54. Found: C, 45.59; H, 9.31; N, 11.42.

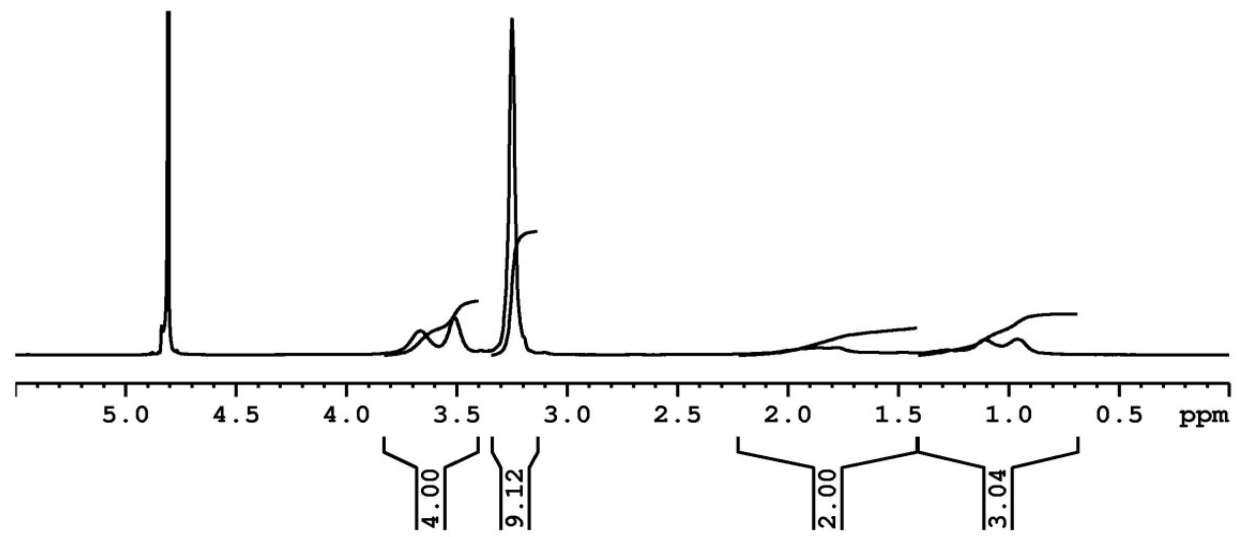

Figure SI-4: ${ }^{1} \mathrm{H}$ NMR spectrum of 2 
Synthesis of 3a: N,N-Dimethyl-p-phenylenediamine (1.63 g, $12.0 \mathrm{mmol})$ was dissolved in 20 $\mathrm{mL}$ of anhydrous THF and transferred to a $100 \mathrm{~mL}$ round-bottomed flask. The solution was then degassed and kept under a dry nitrogen atmosphere. Then $10 \mathrm{~mL}$ of a $2.5 \mathrm{M}$ solution of $n$-butyl lithium in hexane was added dropwise and the solution maintained close to room temperature using an ice bath. To this solution was added, dropwise, a solution made from PMMA $\left(\mathrm{M}_{\mathrm{w}}\right.$ : 100K, $\left.0.2 \mathrm{~g}, 2.00 \mathrm{mmol}\right)$ and $20 \mathrm{~mL}$ THF. After stirring for $24 \mathrm{~h}$, the product mixture was quenched by addition of $1 \mathrm{~mL}$ of isopropanol and concentrated under reduced pressure. The concentrated mixture was then poured into $200 \mathrm{~mL}$ of diethyl ether to precipitate. The polymer was then washed three times with diethyl ether. The crude product 3a was then used for the next step without further purification.

Synthesis of 3: The crude residue $(0.58 \mathrm{~g}, 1.66 \mathrm{mM})$ was dissolved in $\mathrm{MeOH} / \mathrm{MeCN}$ (10 $\mathrm{mL} / 10 \mathrm{~mL})$, followed by addition of iodomethane $(2.36 \mathrm{~g}, 16.6 \mathrm{mM})$. The reaction mixture was then heated to $38{ }^{\circ} \mathrm{C}$. After stirring for $24 \mathrm{~h}$, the product mixture was concentrated under reduced pressure and dissolved in $10 \mathrm{~mL}$ of water. Subsequent dialysis against $2 \mathrm{~L}$ of a $0.1 \mathrm{M}$ $\mathrm{NaCl}$ solution for $24 \mathrm{~h}$, and dialysis against $2 \mathrm{~L}$ of deionized water for $48 \mathrm{~h}$, followed by freeze drying afforded $0.41 \mathrm{~g}(80 \%)$ of 3 as a purple powder having ${ }^{1} \mathrm{H}$ NMR $(500 \mathrm{MHz}$, $\mathrm{D}_{2} \mathrm{O}$ ): $\delta 7.72$ (brs, 2H), 7.48 (brs, 2H), 3.50 (s, 9H), 2.3-1.5 (brm, 2H), 1.5-0.7 (brm, 3H). Anal. Calcd for $\mathrm{C}_{12} \mathrm{H}_{19} \mathrm{~N}_{2} \mathrm{OCl} \cdot 1.5 \mathrm{H}_{2} \mathrm{O}$ (repeat unit): C, 55.42; H, 7.82; N, 9.95. Found: $\mathrm{C}$, 54.52; H, 7.83; N, 9.66.

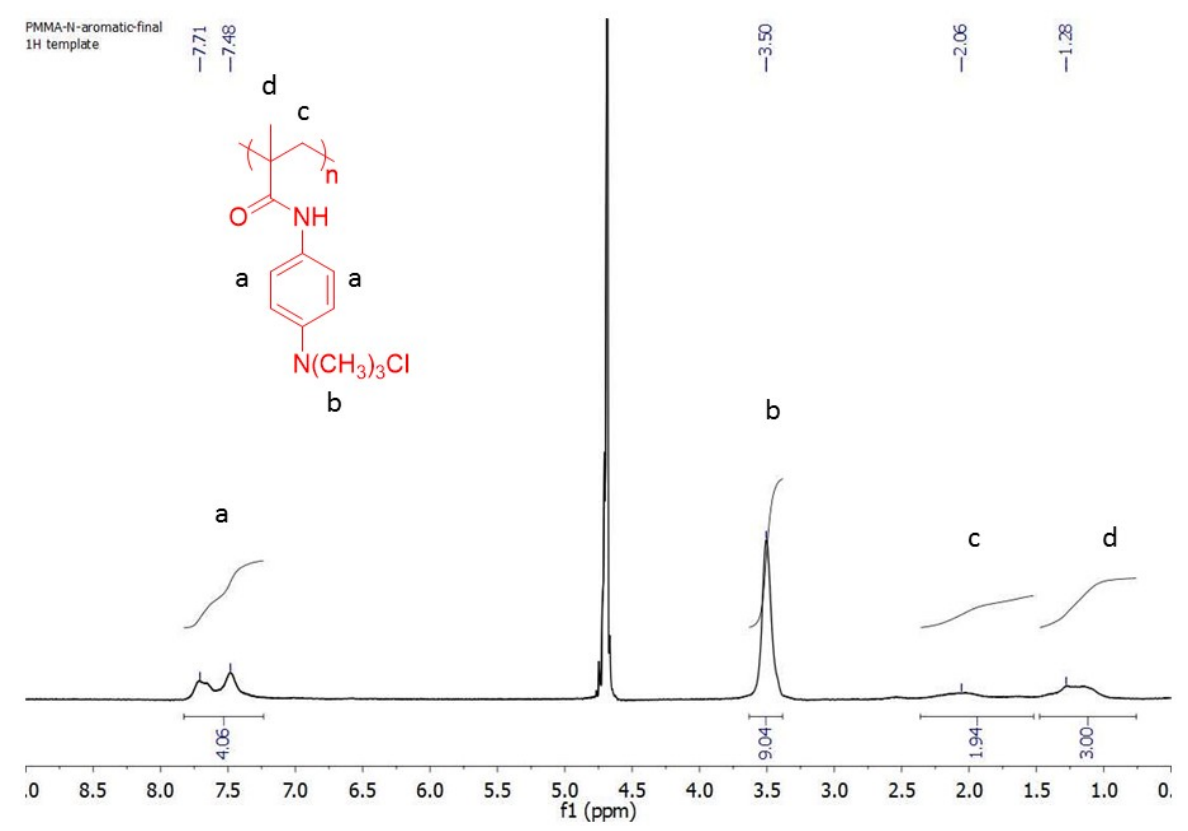

Figure SI-5: ${ }^{1} \mathrm{H}$ NMR spectrum of 3 


\section{Growth Profiles of PEMs}

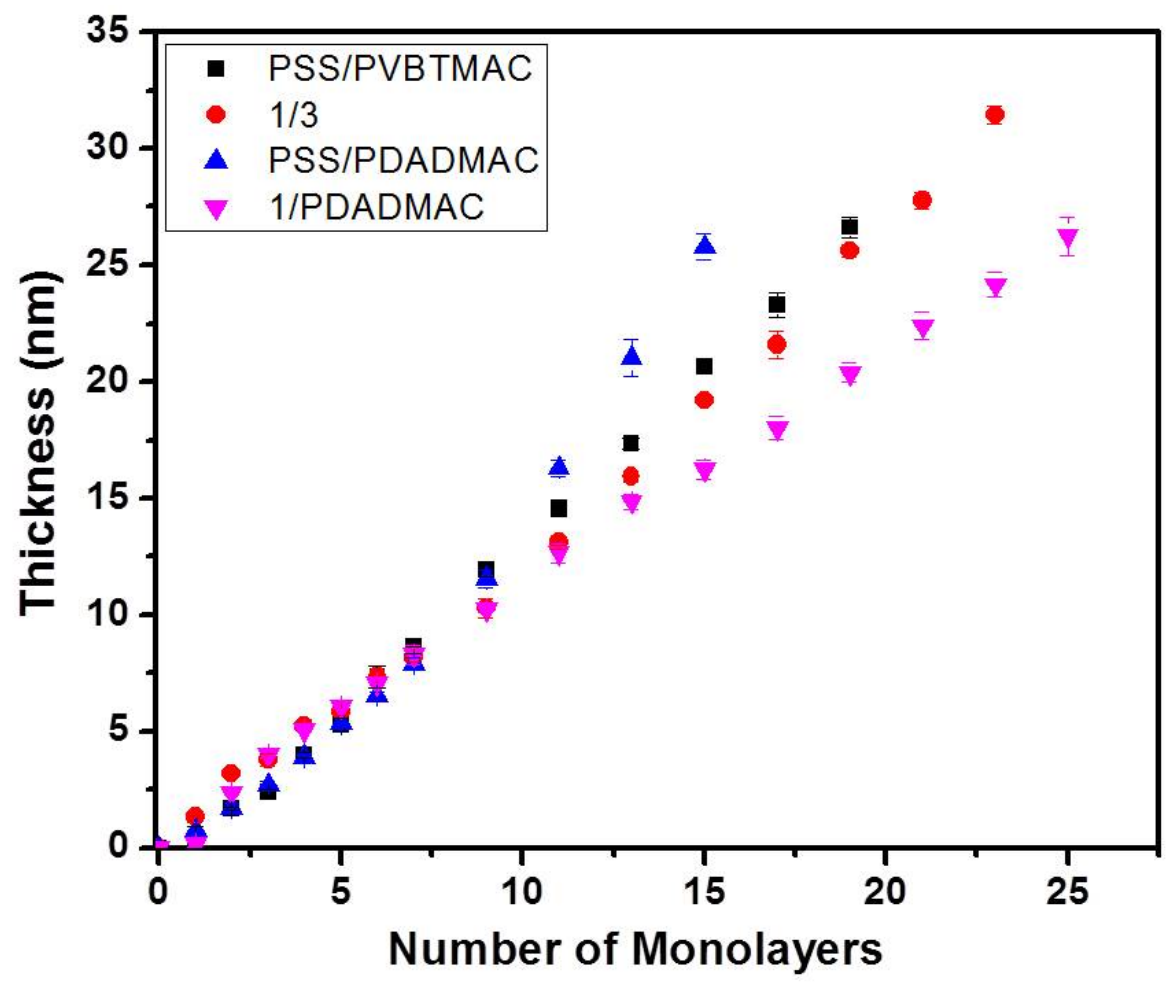

Figure SI-6: Growth profiles for PEMs derived from (A) PSS/PVBTMAC, (B) 1/3, (C) PSS/PDADMAC, (D) 1/PDADMAC, as determined by ellipsometry measurements.

\section{Advancing Contact Angles of PEMs}

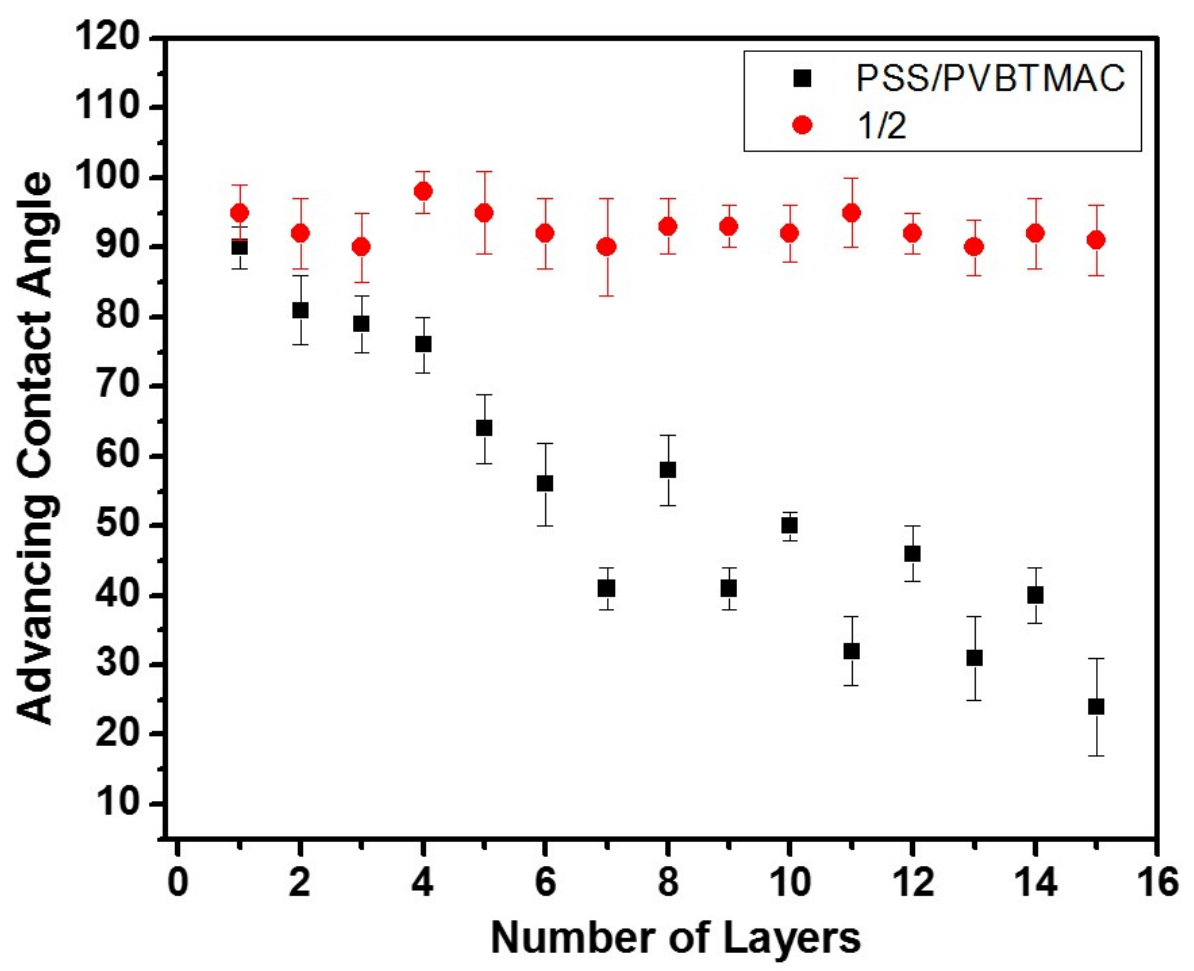

Figure SI-7: Advancing contact angles as a function of number of monolayers for PEMs derived from PSS/PVBTMAC and 1/2. All odd numbers of layers refer to the polyanions. 


\section{Permeability of PEMs}

Table SI-1: Permeances of PEMs

\begin{tabular}{|c|c|c|c|c|c|c|c|c|}
\hline membrane & $\mathrm{n}$ & $\begin{array}{l}\text { PEM } \\
(\mathrm{nm})\end{array}$ & $\begin{array}{l}\mathrm{H}_{2} \\
(\mathrm{GPU})\end{array}$ & $\begin{array}{l}\mathrm{CO}_{2} \\
(\mathrm{GPU})\end{array}$ & $\begin{array}{l}\mathrm{N}_{2} \\
(\mathrm{GPU})\end{array}$ & $\mathrm{H}_{2} / \mathrm{N}_{2}$ & $\mathrm{H}_{2} / \mathrm{CO}_{2}$ & $\mathrm{CO}_{2} / \mathrm{N}_{2}$ \\
\hline \multirow[t]{2}{*}{ PTMSP } & $\begin{array}{l}---- \\
\end{array}$ & $\begin{array}{ll}---- \\
\end{array}$ & 710 & 1800 & 310 & 2.3 & 0.39 & 5.8 \\
\hline & ----- & ----- & 690 & 1700 & 300 & 2.3 & 0.41 & 5.7 \\
\hline \multirow[t]{6}{*}{$(\mathrm{PSS} / \mathbf{3}) \mathrm{n}$} & 6.5 & 19.2 & 195 & 68.2 & 0.85 & 230 & 2.86 & 80 \\
\hline & & & 193 & 65.3 & 0.81 & 240 & 2.96 & 81 \\
\hline & 7.5 & 21.4 & 169 & 60.8 & 0.58 & 290 & 2.78 & 110 \\
\hline & & & 172 & 62.5 & 0.61 & 280 & 2.75 & 100 \\
\hline & 8.5 & 23.9 & 164 & 57.6 & 0.56 & 290 & 2.85 & 100 \\
\hline & & & 145 & 60.2 & 0.60 & 240 & 2.41 & 100 \\
\hline \multirow[t]{4}{*}{ (PSS/PVBTMAC)n } & 7.5 & 20.6 & 131 & 44.9 & 0.44 & 300 & 2.92 & 100 \\
\hline & & & 124 & 48.7 & 0.48 & 260 & 2.55 & 100 \\
\hline & 8.5 & 23.3 & 112 & 40.2 & 0.40 & 280 & 2.79 & 100 \\
\hline & & & 116 & 42.6 & 0.38 & 300 & 2.72 & 110 \\
\hline \multirow[t]{6}{*}{$(\mathrm{PSS} / \mathbf{2}) \mathrm{n}$} & 6.5 & 16.8 & 86.5 & 18.7 & 0.39 & 220 & 4.63 & 48 \\
\hline & & & 92.2 & 19.2 & 0.36 & 260 & 4.80 & 53 \\
\hline & 7.5 & 21.2 & 62.9 & 15.7 & 0.15 & 420 & 4.01 & 100 \\
\hline & & & 65.9 & 15.9 & 0.15 & 440 & 4.14 & 110 \\
\hline & 8.5 & 25.6 & 53.5 & 14.5 & 0.13 & 410 & 3.69 & 110 \\
\hline & & & 52.3 & 13.2 & 0.12 & 440 & 3.96 & 110 \\
\hline \multirow[t]{6}{*}{$(1 / 3) n$} & 6.5 & 15.9 & 69.2 & 14.3 & 0.17 & 410 & 4.84 & 84 \\
\hline & & & 71.0 & 14.4 & 0.18 & 400 & 4.93 & 80 \\
\hline & 7.5 & 19.2 & 68.2 & 13.6 & 0.14 & 490 & 5.01 & 97 \\
\hline & & & 68.4 & 13.0 & 0.13 & 530 & 5.26 & 100 \\
\hline & 8.5 & 21.6 & 44.6 & 12.0 & 0.12 & 370 & 3.72 & 100 \\
\hline & & & 46.1 & 12.5 & 0.12 & 380 & 3.69 & 100 \\
\hline \multirow[t]{4}{*}{ (PSS/PDADMAC)n } & 6.5 & 21.0 & 56.1 & 12.1 & 0.10 & 560 & 4.64 & 120 \\
\hline & & & 59.5 & 13.0 & 0.11 & 540 & 4.58 & 120 \\
\hline & 7.5 & 25.8 & 48.6 & 9.2 & 0.090 & 540 & 5.28 & 100 \\
\hline & & & 46.5 & 8.6 & 0.071 & 650 & 5.41 & 120 \\
\hline \multirow[t]{6}{*}{$(1 / 2) n$} & 12.5 & 20.2 & 43.2 & 7.10 & 0.16 & 270 & 6.08 & 44 \\
\hline & & & 44.8 & 7.91 & 0.23 & 190 & 5.66 & 34 \\
\hline & 13.5 & 22.8 & 30.1 & 4.07 & 0.039 & 770 & 7.40 & 100 \\
\hline & & & 31.5 & 4.19 & 0.041 & 770 & 7.52 & 100 \\
\hline & 14.5 & 24.7 & 26.1 & 3.95 & 0.040 & 650 & 6.61 & 99 \\
\hline & & & 27.0 & 3.46 & 0.036 & 750 & 7.80 & 96 \\
\hline \multirow[t]{6}{*}{ (1/PDADMAC)n } & 8.5 & 18.0 & 40.1 & 6.02 & 0.096 & 420 & 6.66 & 63 \\
\hline & & & 38.2 & 6.90 & 0.091 & 420 & 5.54 & 76 \\
\hline & 9.5 & 20.4 & 29.4 & 3.45 & 0.028 & 1050 & 8.52 & 120 \\
\hline & & & 30.1 & 3.41 & 0.029 & 1040 & 8.83 & 120 \\
\hline & 10.5 & 22.4 & 28.8 & 3.11 & 0.028 & 1030 & 9.26 & 110 \\
\hline & & & 27.1 & 3.08 & 0.030 & 900 & 8.80 & 100 \\
\hline
\end{tabular}




\section{Effective Young's Modulus from Nanoindentation Measurements}

The effective Young's modulus was determined by fitting force-indentation curves to a sphere-on-a-flat contact mechanics model. Depending on the relative magnitude of deformation due to surface forces and external load, two limiting cases can be used to describe force-indentation relationship, corresponding to Jonson-Kendall-Roberts (JKR) or Derjaguin-Muller-Toporov (DMT) models. ${ }^{1}$ We found that both JKR and DMT models could describe force-indentation curves equally well, JKR model resulting in a higher (by up to 35\%) Young's modulus (Table SI-2). We used the results from the JKR model for comparison of mechanical properties of these PEMs, since calculated Tabor elasticity parameter $\mu \approx 3.3$ is representative of the JKR conditions (DMT and JKR regimes are associated with $\mu<0.1$ and $\mu>5$, respectively). The choice of the model did not affect the ranking of the elasticity of PEM samples.

The force-indentation response of an elastic material can be represented in non-dimensional form according to DMT and JKR models as shown in equations SI-1 and SI-2:

$$
\begin{gathered}
\bar{\delta}=(1+\bar{P})^{\frac{2}{3}} \\
\bar{\delta}=\left(1+(1+\bar{P})^{\frac{1}{2}}\right)^{\frac{1}{3}}\left((1+\bar{P})^{\frac{1}{2}}-\frac{1}{3}\right)
\end{gathered}
$$

Here, the non-dimensional indentation $\bar{\delta}$ and non-dimensional applied load $\bar{P}$ are given by:

$$
\begin{gathered}
\bar{\delta}=\frac{\delta}{\delta^{*}} \quad \delta^{*}=\left(\frac{F_{a d h}}{K \sqrt{R}}\right)^{\frac{2}{3}} \\
\bar{P}=\frac{P}{F_{a d h}}
\end{gathered}
$$

where $R$ is the radius of curvature of the AFM probe, $K=\frac{4}{3} \frac{E}{1-v^{2}}$ is the elastic constant ( $E$ is the Young's modulus and $v$ is the Poisson's ratio of the material), and $F_{a d h}$ is the adhesion force. For each indentation curve, we set $F_{a d h}$ and $\delta^{*}=\left(\frac{F_{a d h}}{K \sqrt{R}}\right)^{\frac{2}{3}}$ as fitting parameters leading to the determination of Young's modulus $E$ for known (fixed) values of $R$ and $v$. 


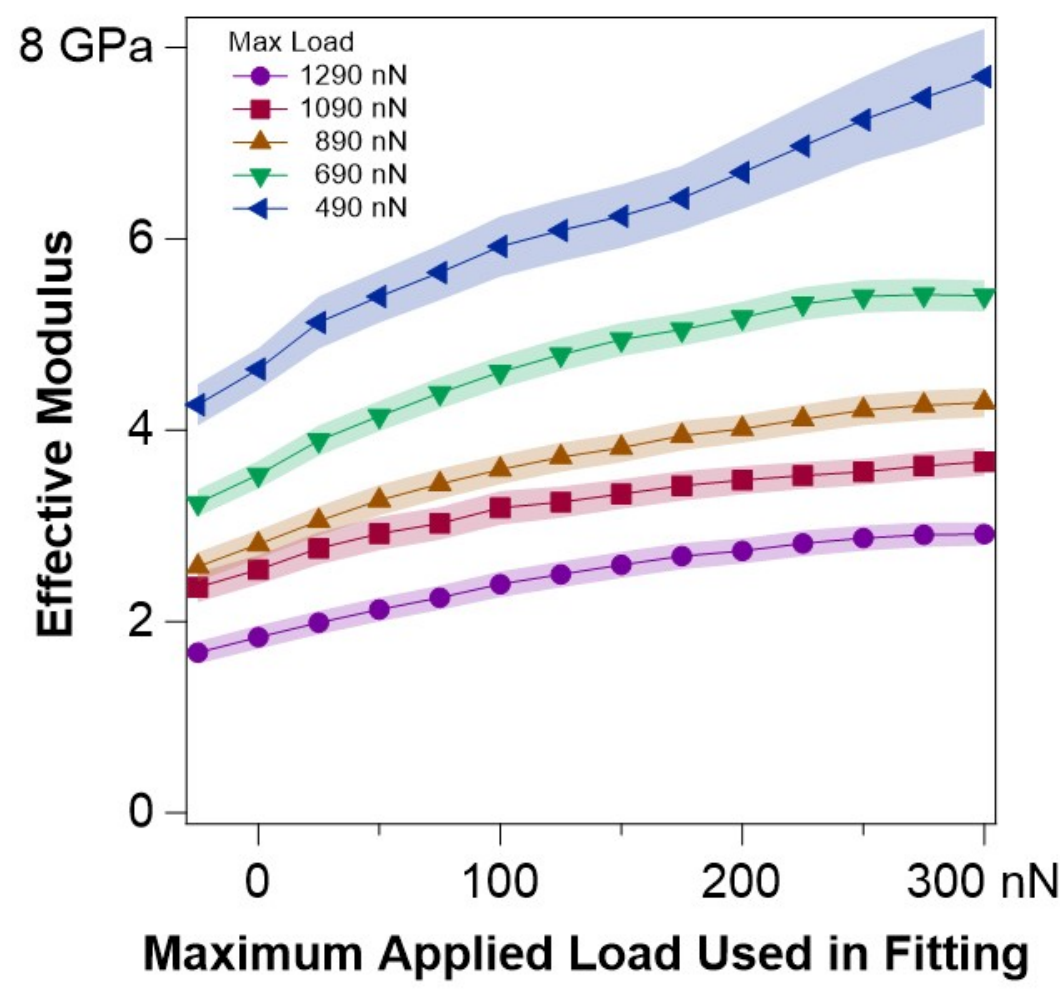

Figure SI-8: Effective modulus versus range of fit to JKR model for different maximum loads

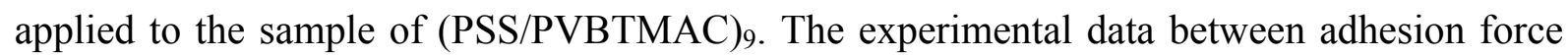
and maximum load are fitted to JKR model as illustrated in Figure 5 in the main text. The points are mean values from approximately 100 force-indentation curves, the shaded bands represent $95 \%$ confidence intervals.

Table SI-2: Effective Young's moduli of PEM films determined on Si substrates using $F_{\max }=$ $0 \mathrm{nN}$.

\begin{tabular}{|c|c|c|c|c|}
\hline \multirow{2}{*}{ PEM composition } & \multicolumn{2}{|c|}{$\begin{array}{c}\text { DMT Young's modulus } \\
(\mathrm{GPa})\end{array}$} & \multicolumn{2}{c|}{ JKR Young's modulus (GPa) } \\
\cline { 2 - 5 } & $\begin{array}{c}\text { at maximum } \\
\text { loads: } 1290 \mathrm{nN} \\
-490 \mathrm{nN}\end{array}$ & $\begin{array}{c}\text { at maximum } \\
\text { load } 1090 \\
\mathrm{nN}\end{array}$ & $\begin{array}{c}\text { at maximum } \\
\text { loads: } 1290 \mathrm{nN} \\
-490 \mathrm{nN}\end{array}$ & $\begin{array}{c}\text { at maximum } \\
\text { load } 1090 \mathrm{nN}\end{array}$ \\
\hline$(\mathbf{1} / \mathbf{2})_{13.5}$ & $3.3-6.0$ & $3.56 \pm 0.19$ & $2.9-7.2$ & $4.83 \pm 0.21$ \\
\hline$(\mathbf{1} / \text { PDADMAC })_{9.5}$ & $2.3-4.2$ & $3.49 \pm 0.34$ & $2.5-4.8$ & $4.45 \pm 0.24$ \\
\hline$(\text { PSS/3 })_{7.5}$ & $2.6-3.3$ & $2.91 \pm 0.25$ & $2.8-3.8$ & $2.76 \pm 0.23$ \\
\hline$(\text { PSS/PVBTMAC })_{9.5}$ & $1.4-3.0$ & $2.09 \pm 0.23$ & $1.8-3.0$ & $2.27 \pm 0.24$ \\
\hline
\end{tabular}




\section{AFM Images of PEMs}

Topography imaging was done using MFP-3D atomic force microscope (Asylum Research, Santa Barbara, CA) in tapping mode.

Table SI-3: Roughness of PEM films measured over $20 \mu \mathrm{m} \times 20 \mu \mathrm{m}$ area.

\begin{tabular}{|c|c|}
\hline PEM Composition & Rms Roughness \\
\hline$(\mathbf{1} / \mathbf{2})_{13.5}$ & $7.2 \mathrm{~nm}$ \\
\hline$(\mathbf{1} / \text { PDADMAC })_{9.5}$ & $0.8 \mathrm{~nm}$ \\
\hline$(\text { PSS / })_{7.5}$ & $1.8 \mathrm{~nm}$ \\
\hline$(\text { PSS / PVBTMAC })_{8.5}$ & $2.4 \mathrm{~nm}$ \\
\hline$(\text { PSS / PVBTMAC })_{9}$ & $3.8 \mathrm{~nm}$ \\
\hline$(\text { PSS / PVBTMAC })_{9.5}$ & $2.8 \mathrm{~nm}$ \\
\hline
\end{tabular}




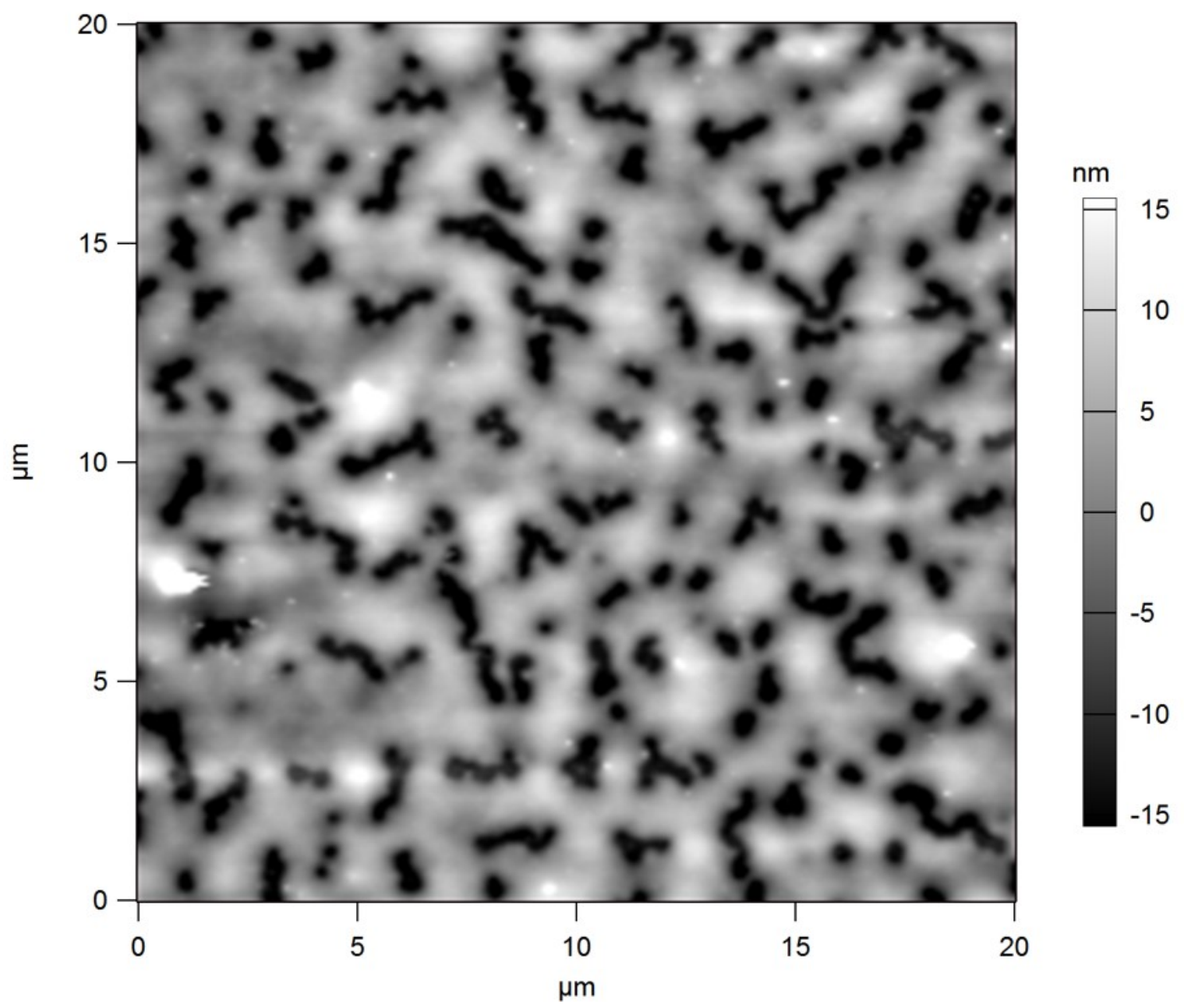

Figure SI-9: Tapping mode topography of [( $\left.1 / 2)_{13.5}\right]$ as determined by AFM

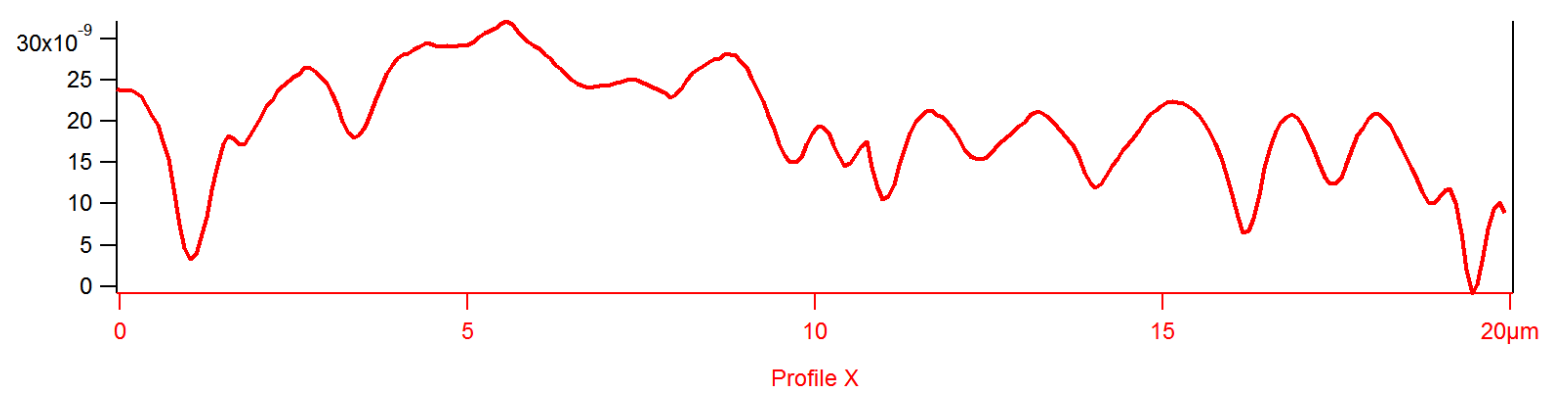

Figure SI-10: Profile of [( 1/2 $\left.)_{13.5}\right]$ as determined by AFM 


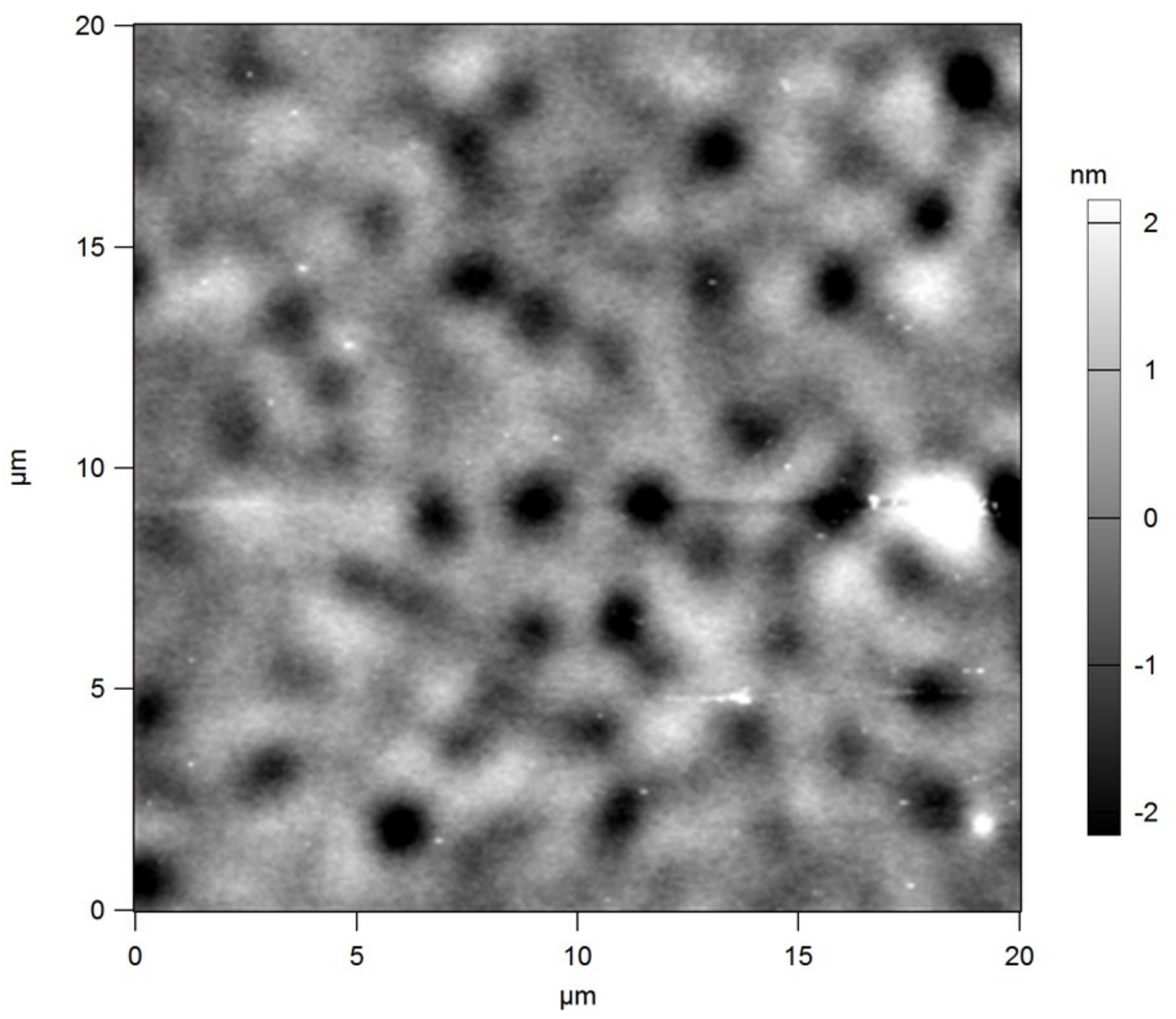

Figure SI-11: Height profile of [( 1/ PDADMAC ) 9.5] as determined by AFM

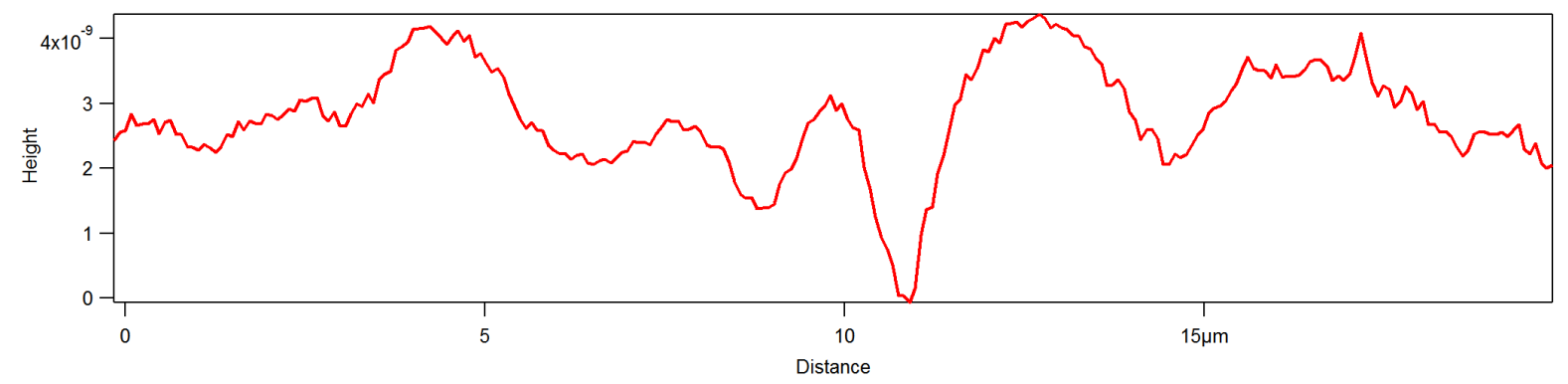

Figure SI-12: Height profile of [( 1/ PDADMAC ) 9.5] as determined by AFM 


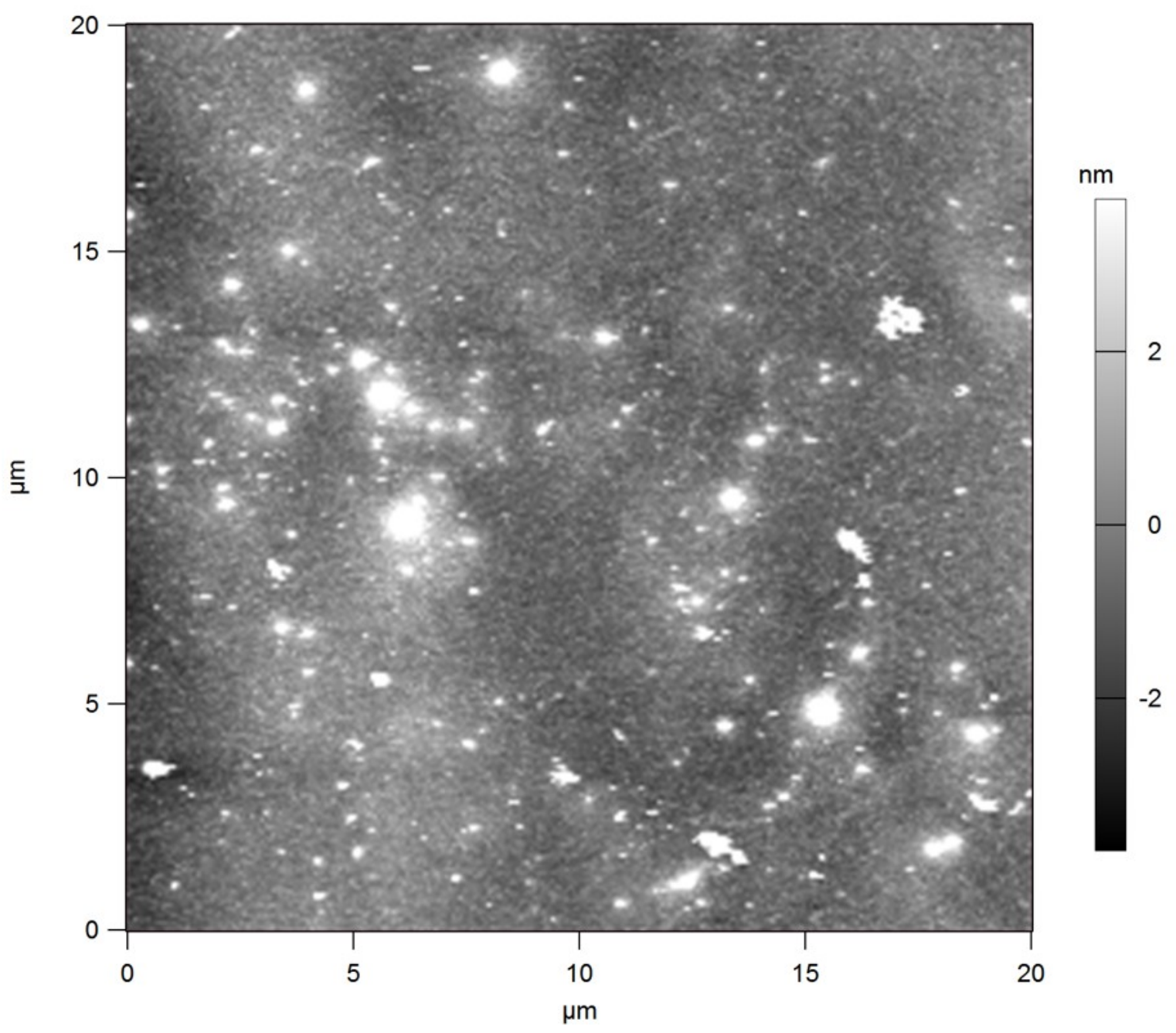

Figure SI-13: Topography of [( PSS/3 ) 7.5] as determined by AFM

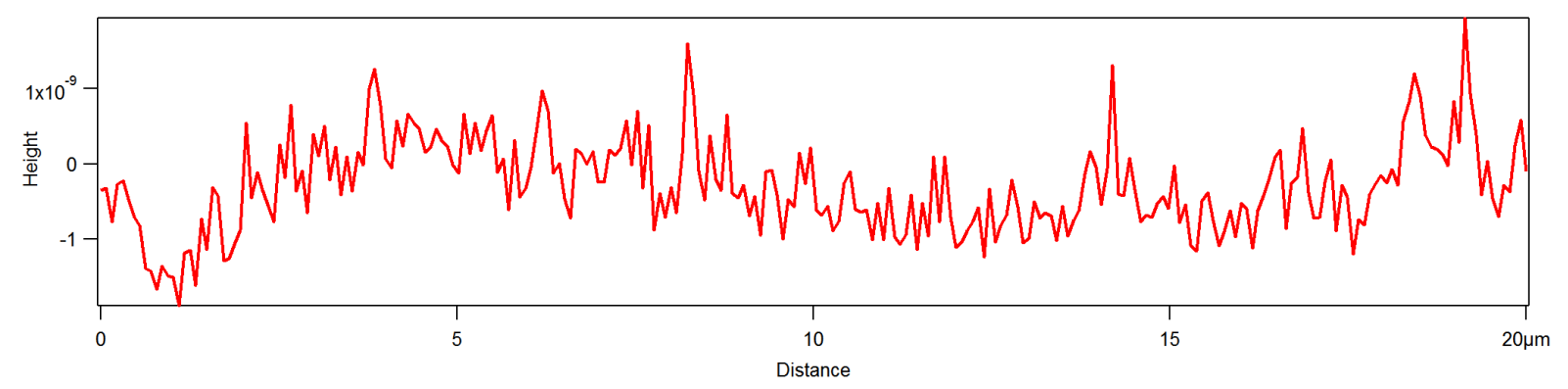

Figure SI-14: Height profile of [( PSS/3 $)$ 7.5] as determined by AFM 


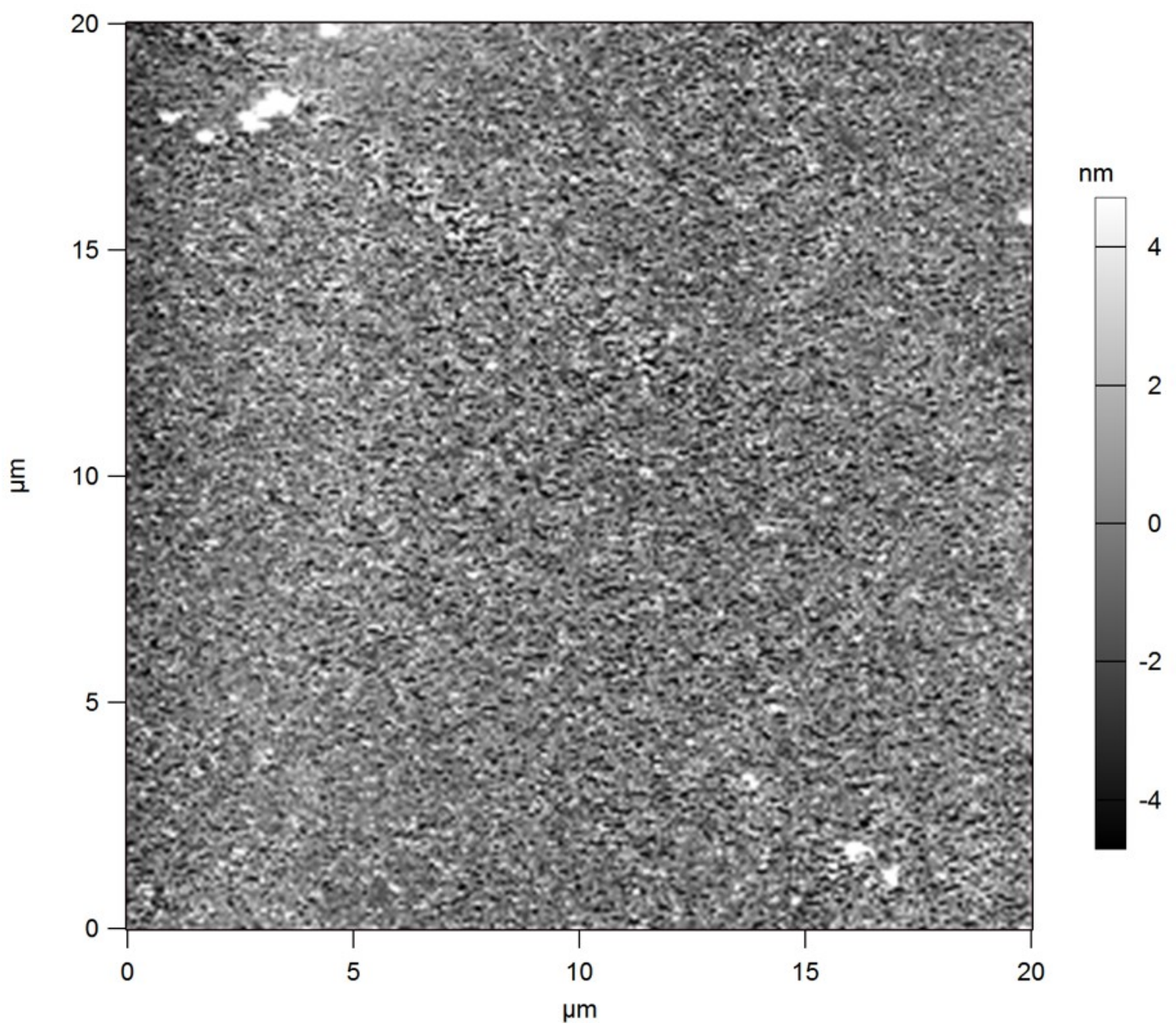

Figure SI-15: Topography of [( PSS/PVBTMAC ) $\left.{ }_{8.5}\right]$ as determined by AFM

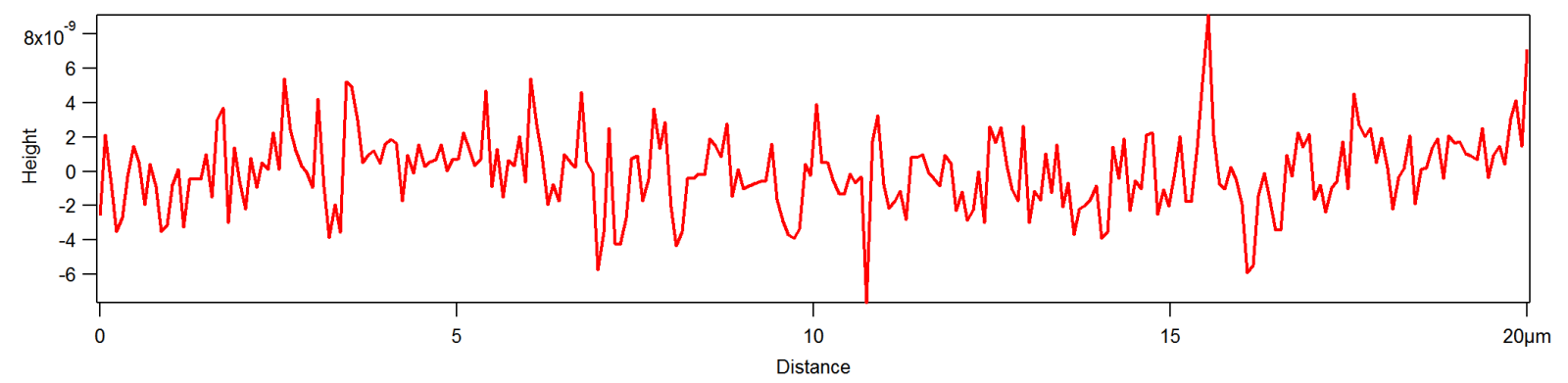

Figure SI-16: Height profile of [( PSS/PVBTMAC ) 8.5$]$ as determined by AFM 


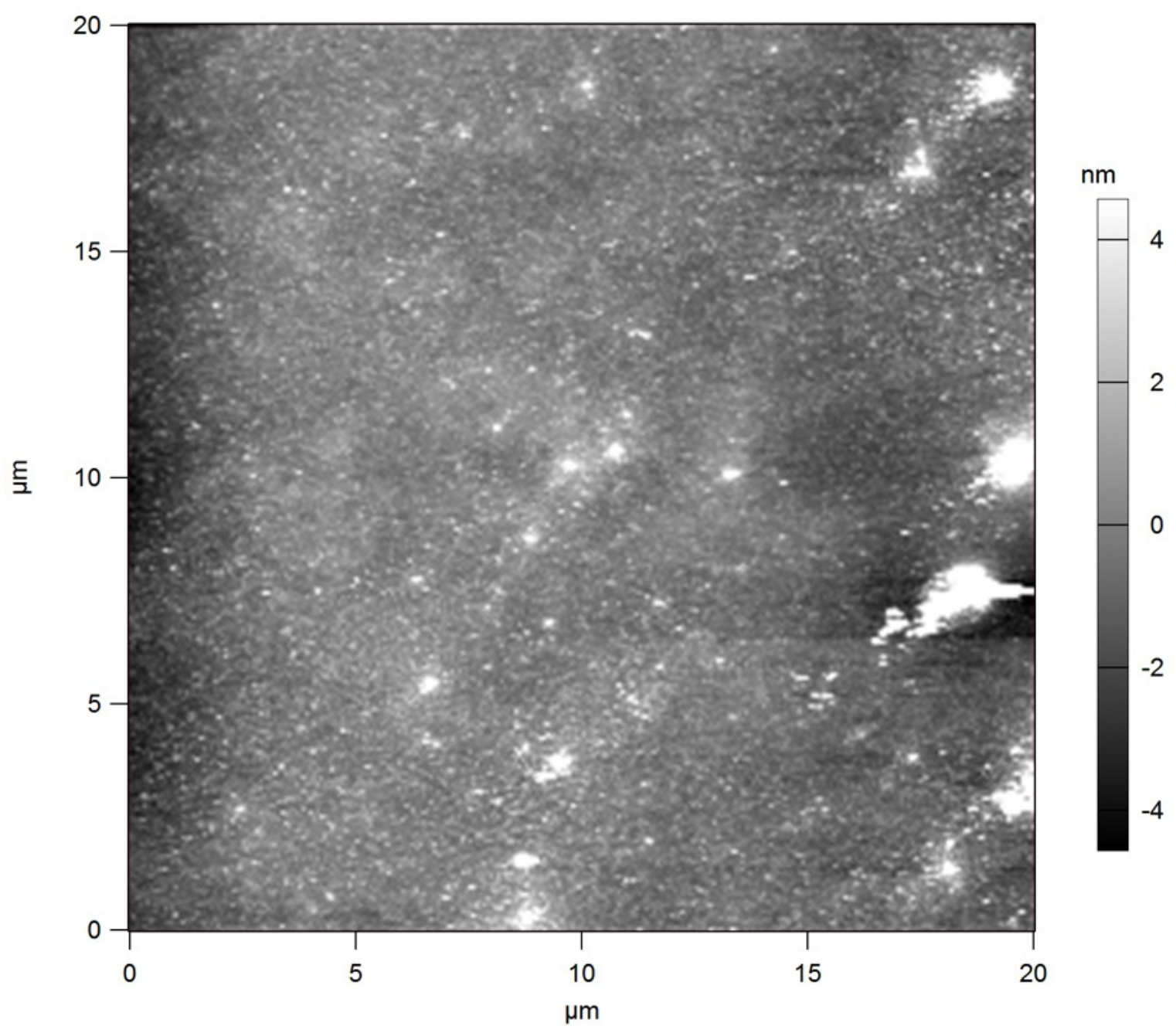

Figure SI-17: Topography of [( PSS/PVBTMAC $\left.)_{9}\right]$ as determined by AFM

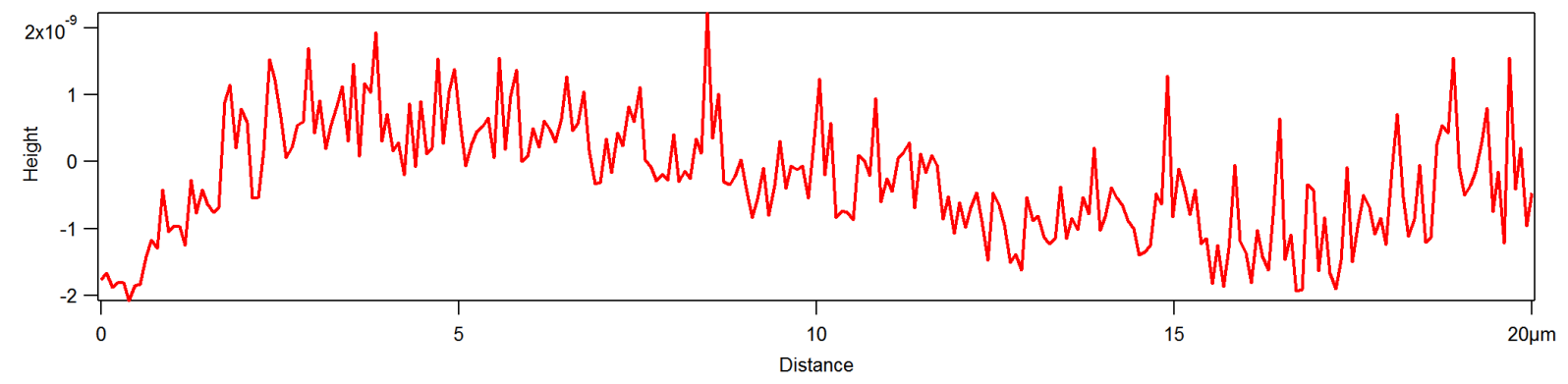

Figure SI-18: Height profile of [( PSS/PVBTMAC ) 9 ] as determined by AFM 


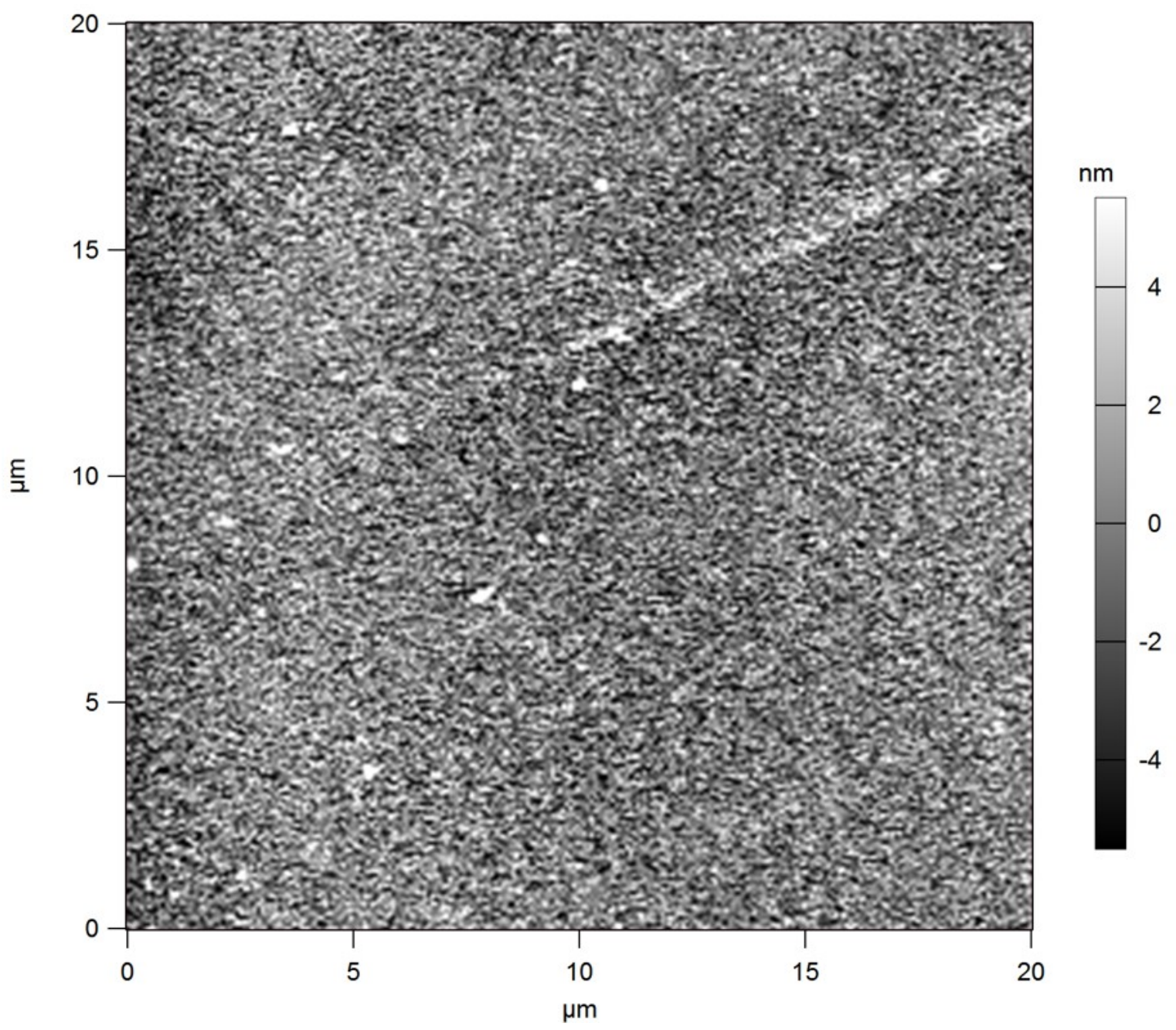

Figure SI-19: Topography of [( PSS/PVBTMAC $\left.)_{9.5}\right]$ as determined by AFM

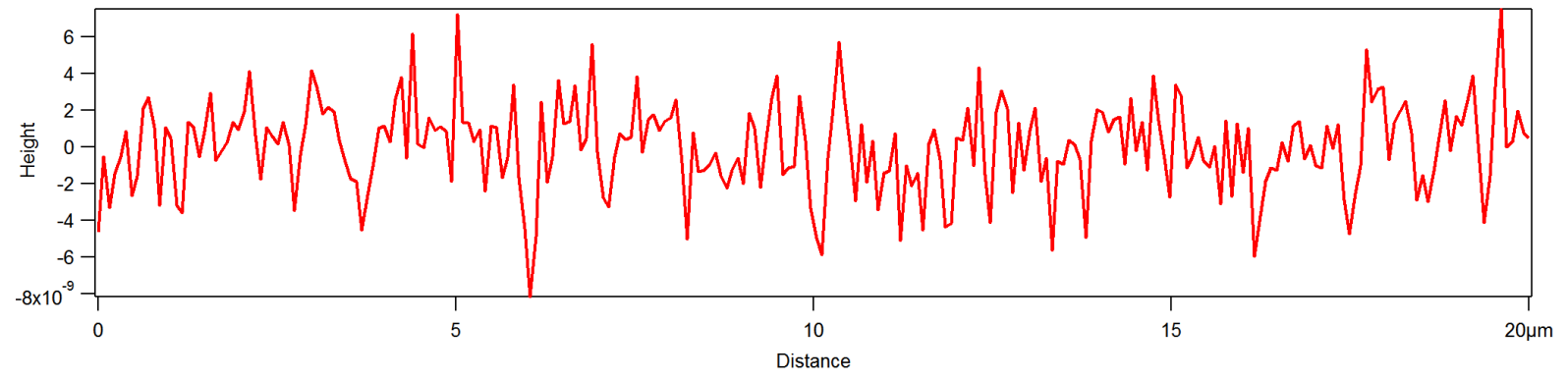

Figure SI-20: Height profile of [( PSS/PVBTMAC ) 9.5 ] as determined by AFM 

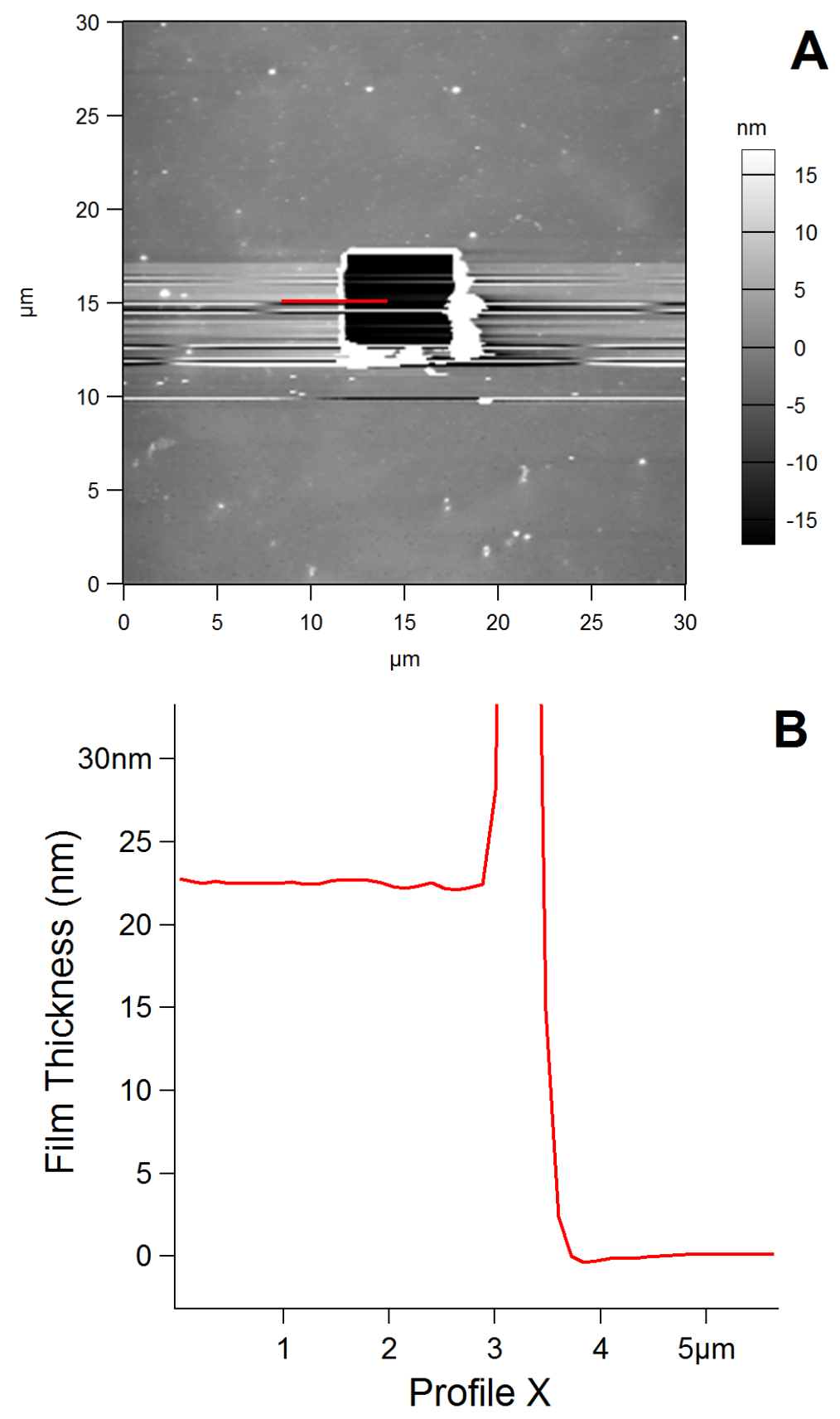

Figure SI-21: (A) AFM topography image of $(\mathbf{1} / \mathbf{2})_{14.5}$; red line indicates where profile was taken. (B) One-dimensional profile of sample height showing the surface of the film, the material buildup from film removal, and the surface of the substrate. AFM nanoscratching experiments were performed by scanning a $5 \times 5 \mu \mathrm{m}$ area in contact mode. The tip was held at $115 \mathrm{nN}$ load. This force was sufficient to remove the PEM film from the OTS-modified Si wafer. A $20 \times 20 \mu \mathrm{m}$ image (centered on $5 \times 5 \mu \mathrm{m}$ previous scan) was then acquired in the tapping mode. The thickness was determined from the 1-D profile as the difference in heights between areas corresponding to intact and scratched out films. 
Table SI-4: Comparison of film thickness measurements.

\begin{tabular}{|c|c|c|}
\hline \multirow{2}{*}{ PEM Composition } & \multicolumn{2}{|c|}{ Thickness (nm) } \\
\cline { 2 - 3 } & Ellipsometry & AFM \\
\hline$(\mathbf{1} / \mathbf{2}) 14.5$ & $24.7 \pm 0.4$ & $23.5 \pm 0.1 \mathrm{~nm}$ \\
\hline
\end{tabular}

Table SI-5: Effective Young's moduli of PSS/PVBTMAC PEM films having different top layers (results from fits to JKR model).

\begin{tabular}{|c|c|c|c|}
\hline \multirow{2}{*}{ PEM composition } & \multirow{2}{*}{ Termination } & \multicolumn{2}{|c|}{ Young's modulus (GPa) } \\
\cline { 3 - 4 } & & $\begin{array}{c}\text { at maximum loads: } \\
1290 \mathrm{nN}-490 \mathrm{nN}\end{array}$ & $\begin{array}{c}\text { at maximum load } \\
1090 \mathrm{nN}\end{array}$ \\
\hline (PSS/PVBTMAC) 8.5 & PSS & $1.5-2.4$ & $1.85 \pm 0.09$ \\
\hline (PSS/PVBTMAC) 9 & PVBTMAC & $2.2-5.4$ & $2.99 \pm 0.18$ \\
\hline (PSS/PVBTMAC) 9.5 & PSS & $1.8-3.0$ & $2.27 \pm 0.24$ \\
\hline
\end{tabular}

\section{References}

[1] Vezenov, D. V.; Noy, A.; Ashby, P. J. Chemical force microscopy: probing chemical origin of interfacial forces and adhesion. Adhes. Sci. Technol., 2005, 19, 313-364. 